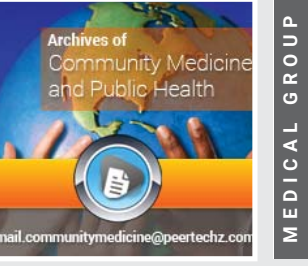

\title{
Histrionic personality disorder: Definition, clinical profiles, differential diagnosis and therapeutic framework
}

Received: 18 December, 2020

Accepted: 04 January, 2021

Published: 05 January, 2021

*Corresponding authors: Dr. Giulio Perrotta, Psychologist sp.ing in Strategic Psychotherapy, Forensic Criminologist, Lawyer sp.ed SSPL, Researcher, Essayist, Italy, E-mail: giuliosr1984@hotmail.it

https://www.peertechz.com

\section{Check for updates}

\section{Giulio Perrotta*}

Psychologist sp.ing in Strategic Psychotherapy, Forensic Criminologist, Lawyer sp.ed SSPL, Researcher, Essayist, Italy

\begin{abstract}
Starting from the general concept of "histrionic personality", the present work focuses on the essential aspects of personality disorder that defi ne the clinical and diagnostic contexts, laying the foundations for a correct differential diagnosis, without neglecting the neural characteristics developed by the scientific community. The discussion ends with the best suggested therapeutic approaches.
\end{abstract}

\section{Contents of the manuscript}

Histrionic personality disorder is a personality disorder in Cluster B of the Diagnostic and Statistical Manual of Mental Disorders, Fifth Edition (DSM-V) [1], in which impulsivity, high emotionality and drama predominate, along with Borderline, Antisocial and Narcissistic Disorder. It is essentially characterised by intense emotionality, expressed in a theatrical manner, and by constant attempts to obtain attention, approval and support from others through covert or overtly seductive behaviour; in addition to the dramatic and inappropriately seductive interpersonal style, impressionability, a tendency to somatisation and novelty seeking characterise this disorder. This disorder would appear to be more common among women than men, but this could be due to cultural conditioning of the diagnoses rather than a real difference in distribution between the sexes $[2,3]$.

One of the most widely accepted aetiological theories for histrionic personality disorder is that it has a dual origin: biological and psychosocial. From the biological point of view, people suffering from this disorder are said to have a temperament characterised by hypersensitivity and an external search for gratification. On the psychosocial level, people who have developed histrionic personality disorder often experienced difficulties in satisfying their legitimate needs for attention and care during childhood. Some of these persons were appreciated by significant figures, particularly their parents, for their pleasant appearance and for their skills as entertainers, rather than for their way of being, so they learned that, in order to satisfy their affective needs, one must use physical appearance and seductiveness. Other people with these disorders received attention and care as children only when they were ill, so they learned to seek care only through physical complaints [2,4-7].

For a diagnosis of histrionic personality disorder, patients must present a persistent pattern of excessive emotionality and attention-seeking, characterised by at least five of the following clinical signs [3].

a) Distress when they are not the centre of attention.

b) Interaction with others that is inappropriately sexually seductive or provocative.

c) Changeable instability and often shallow expression of emotions.

d) Constant use of physical appearance to draw attention to themselves. 
e) Language that is extremely impressionistic and vague.

f) Dramatisation of the self, theatricality, and extravagant expression of emotions.

g) Suggestibility (they are easily influenced by others or situations).

h) Interpretation of relationships as more intimate than they are.

In addition, symptoms must begin in early adulthood.

Comorbidities are common, especially other personality disorders (antisocial, borderline, narcissistic) $[8,9]$, suggesting that these disorders share a biological vulnerability or questioning whether histrionic personality disorder is a separate disorder. Common are anxiety, mood, depressive, bipolar and somatic disorders, as well as delusional and paranoid symptoms, addictions and sexual behaviour disorders, and often simulated attempts at suicide risk (to attract attention) [3,10-35]. In the new nosographic formulation contained in the PICI-1 (version TA), histrionic disorder retains its characteristics, but is better integrated with the symptomatology shared with the other disorders in its cluster [36-38].

Histrionic personality disorder can be distinguished from other personality disorders based on the following characteristics: [3].

\section{Narcissistic personality disorder}

Patients with narcissistic personality disorder also seek attention, but unlike those with histrionic personality disorder, they want to feel admired or elevated; patients with histrionic personality disorder are not as demanding about the kind of attention they receive and do not mind being thought of as cute or silly.

\section{Borderline personality disorder}

Patients with borderline personality disorder see themselves as bad and feel emotions intensely and deeply; those with histrionic personality disorder do not see themselves as bad, although their dependence on the reaction of others may result from low self-esteem.

\section{Dependent personality disorder}

Patients with dependent personality disorder, like those with histrionic personality disorder, try to be close to others, but are more anxious, inhibited, and submissive (because they are worried about rejection); patients with histrionic personality disorder are less inhibited and more exuberant.

People with histrionic personality disorder feel uncomfortable or unappreciated when they are not the centre of attention. For this reason they continually try to capture the interest of others with behaviour that is theatrical (e.g. exaggeration of life episodes, invention of stories, dramatic descriptions of their physical and emotional state), provocative (e.g. instigation) or seductive (e.g. flattery, sexual provocation, gifts). These persons may initially fascinate new acquaintances by their enthusiasm, hyper-sociability, tendency to involve, display of confidence and seductiveness. In particular, their seductive behaviour is inappropriate in inappropriate contexts (e.g. at work) and also towards people for whom they have no real emotional or sexual interest (e.g. employers, friends). The body can be used to attract the attention of others, becoming not only seductive, but also sick. The focus on the approval of others, rather than on one's own internal experiences, results in a propensity to consider oneself only in relation to others and, therefore, to experience a poor sense of personal identity. Dramatic and superficial emotional expression is another distinctive feature of this disorder. People suffering from histrionic personality disorder have intense and blatant emotional displays (e.g. crying uncontrollably over a minor event, hugging people they have only just met), which flare up and die quickly and do not seem to be experienced in depth. These people can be accused of simulating feelings that they would not authentically experience. In particular, the communication style of people with histrionic personality disorder is theatrical (e.g., gesticulating, use of facial expressions), impressionistic and lacking in detail: these people may express opinions convincingly, but the underlying reasons are often lacking in data and details to support them. Another characteristic feature of histrionic personality disorder is that people consider their relationships to be more intimate than they really are (e.g. regarding an acquaintance as a close friend, fantasising about acquaintances in a romantic way, allowing themselves to call people they have just met by their first name). In reality, sufferers have difficulty in achieving genuine emotional intimacy with the people with whom they relate. In their relationships, they may, for example, play a part (e.g., the victim, the princess) or try to control the other person through emotional manipulation and seduction, without being aware of it. They are extremely dependent on external attention, approval and support, are very sensitive to rejection and fearful of separation. In order to avoid relationship breakdown, they may resort to extreme behaviour aimed at attracting the attention of the other person (e.g. sexual promiscuity, selfharm, suicide attempts). In relationships, they may seek out authority figures to whom they attribute extraordinary gifts and magical solutions to their problems. Another characteristic of people with this disorder is a high degree of suggestibility: their opinions and feelings can be easily influenced by the beliefs and moods of others, by impressions and enthusiasms of the moment, by simple circumstances. Personal values and interests, for example, may vary with the values and interests of the partner of the moment. They may also be intolerant of frustration and exposed to boredom, so they may seek immediate gratification of their needs (e.g. abandoning a project after initial enthusiasm because it is tiring) and considerable stimulation (e.g. seeking new and exciting activities such as promiscuous sex, neglecting a lasting relationship and seeking excitement in a new relationship). People with histrionic personality disorder are often concerned about their physical appearance and take great care of it (e.g. they spend a considerable amount of time, energy and money on clothing and body care) as a means of attracting attention to themselves. These people frequently seek compliments on their 
appearance and can be easily and excessively upset by a critical comment on it. The manifestation of histrionic personality disorder may be influenced by sex-role stereotypes, whereby a man and a woman with this disorder may embody caricatures of masculinity (the athletic, womanizing 'macho') and femininity (the over-emotional, aesthetically well-groomed 'femme fatale') respectively. On the other hand, this disorder can also manifest itself in men in the form of approvalseeking and passive behaviour [10]. A recent study has shown that histrionic individuals, such as borderline and narcissistic individuals, have very high levels of alexithymia and thus a low ability to recognise their own and other people's emotions [14].

Certain features of histrionic personality disorder can also be found in other disorders, from which this disorder should be distinguished. Rapidly changing emotions, attention-seeking and manipulative behaviour, for example, are also characteristic of borderline personality disorder, but in the latter there is also self-destructiveness, angry breakdowns of interpersonal relationships and more intense states of emptiness and altered identity. Both people with histrionic personality disorder and those with antisocial personality disorder tend to be superficial, manipulative, seductive, impulsive and in search of new and exciting situations, but the former, unlike the latter, show more intense emotional reactions, typically do not engage in antisocial behaviour and carry out manipulations to obtain attention and care, rather than profit, power and material gratification. Narcissistic personality disorder sufferers also crave the attention of others, but whereas they usually seek praise for their supposed superiority, histrionic personality disorder sufferers are also willing to appear fragile and dependent in order to gain attention. Narcissistic personality disorder sufferers may also exaggerate the intimacy of their relationships, but generally emphasise the social or economic position of their acquaintances. People with dependent personality disorder are also highly dependent on others for praise and support, but they do not have the excessive emotionality and theatrical style that characterises histrionic personality disorder [10].

Sufferers of this disorder can compromise their emotional, social and professional relationships by implementing strategies that tend to be manipulative. The theatrical interpersonal style may lead others to consider them superficial and inauthentic. Pressing and dramatic demands for help and care (e.g. showing fear or being very depressed, threatening or attempting suicide), carried out when one feels that one is not considered or has to face life's difficulties alone, may drive away exasperated partners, relatives and friends. Provocative or seductive behaviour can also be perceived by people of the same sex as threatening to their relationship and can lead to competitiveness or distance in the relationship. At work, this behaviour may be inappropriate and may lead to low esteem or devaluation at work [12].

It is useful to analyse the psychological characteristics of individuals with histrionic personality disorder in terms of their views of themselves and others, intermediate and deepseated beliefs, coping strategies and core emotions [11,14].

\section{Self-image}

Since they feel inadequate and vulnerable to being ignored, they manifest a compensatory self-image of fashionable people who make their mark and therefore deserve attention.

\section{View of others}

They view others favourably as long as they manage to attract their attention, entertainment and affection. They try to form strong alliances with others, with the condition that they are at the centre of the group and that others play the role of attentive audience. In contrast to narcissistic personalities, histrionics are very involved in minute-to-minute interactions with others and their self-esteem depends on receiving continuous expressions of appreciation.

\section{Intermediate and deep beliefs}

Histrionics may have rules that fall under intermediate beliefs, such as 'you should express your feelings', 'you should be funny', 'you should show others that they have hurt you'. Some of their assumptions are "if I entertain or amuse others then I am worthy", "if I fail to capture the attention of others, then I am worthless, others will abandon me", "if others do not respond, they are unfair", "if I fail to capture their attention, I am powerless". Deep-seated beliefs are "I am fundamentally unattractive" and compensatory beliefs include "I am lovable, funny and interesting", "I am deserving of admiration", "people are there to admire me and I make my bet", "they don't have the right, they deny me my due".

\section{Coping strategies}

They use dramatisation and demonstrate in every way to keep people attached to them. When they fail to do so, they believe they are being treated unfairly, and try to gain approval through theatrical expressions of grief and anger: they cry, engage in aggressive behaviour, attempt suicide, etc.

\section{Main emotions}

The most prevalent is joy, often combined with hilarity and other high-tone emotions when successfully entertaining people. Histrionic individuals usually experience an undercurrent of anxiety and mild dysphoria, reflecting fear of rejection. When they are rejected, their emotion can quickly change to anger or sadness.

Studies showing which treatments are effective in treating histrionic personality disorder are currently scarce. Among the treatments with some evidence of effectiveness are the following. The preferred treatment is individual psychotherapy, accompanied by pharmacotherapy if necessary. Psychodynamic psychotherapy, postulating that the basic dynamic in people suffering from histrionic personality disorder is the unresolved attempt to have all their needs satisfied by someone else, attempts to identify with the patient the origin of this dynamic and the so-called neurotic strategies (e.g. seduction, illogical thinking) used to satisfy their needs. A distinctive feature of this type of treatment is the interpretation of the transference (emotions and thoughts experienced in a past significant 
relationship and shifted to a current figure) of the patient towards the therapist. Although the evidence for the efficacy of group treatments for this disorder is currently scarce, psychodynamic group psychotherapy seems to be effective for histrionic patients who present greater difficulties and suffering. The group context, in fact, would help them to modulate both the transference with the therapist and the search for attention, approval and care. The literature also contains protocols for the treatment of these people as a couple. Such treatment is usually required after strong disagreements within the couple or because of an imminent threat of separation. Sperry and Maniacci have developed a treatment that integrates the systemic, psychodynamic and cognitivebehavioural approaches and is aimed at couples consisting of one partner with histrionic personality disorder and the other partner with obsessive-compulsive personality disorder (this type of couple is frequently formed because in it the partners assume complementary roles, such as 'support seeker' and 'responsibility taker'). This treatment process involves three phases: establishing the therapeutic alliance, restoring balance within the couple and modifying the partners' individual dynamics. The first two phases involve both partners at the same time, while the third is carried out in individual sessions. In the case of histrionic personality disorder, pharmacological therapy is essentially used to support individual psychotherapy. This recourse occurs when the patient presents symptoms such as depression, anxiety and physical symptoms of psychological origin (e.g. psychogenic migraine). In particular, in the presence of depression, cyclic antidepressants or serotoninergics may be indicated, while in the presence of depressive symptoms accompanied by intense sensitivity to rejection, desperate attention-seeking, pretentiousness, hyperphagia and hypersomnia, anti-MAO drugs are the most effective. SSRIs such as fluoxetine and sertraline have been shown to be effective for people with greater difficulties, particularly those with emotional instability and impulsiveness. Within the framework of cognitive behavioural therapy, several treatment programmes have been implemented for personality disorders. The following treatments have already shown some evidence of effectiveness in treating histrionic personality disorder. Beck and Freeman's cognitive therapy for personality disorders is a cognitive-behavioural treatment that focuses on recognising and challenging dysfunctional beliefs about oneself, others and the world. These beliefs are said to be generated by distortions of reality (cognitive distortions) and to constitute cognitive schemata (basic cognitive structures that allow experience and behaviour to be organised). In the treatment of histrionic personality disorder, the patient is first of all helped to identify his emotions, thoughts and the events to which they are related, as he would find it difficult to carry out these operations. This work, together with the evaluation of the consequences of one's actions, would help the patient to lower his dysfunctional impulsiveness. Then the therapist works with the patient to identify and modify his dysfunctional central beliefs: "I am inadequate and unable to manage my life", "I must be loved by everyone to be of value" and "The loss of a relationship is disastrous". The belief that one is incapable of taking care of oneself leads people with this disorder to constantly seek attention and care from others. The second belief induces rejection sensitivity, approval seeking, and the urge to act in relation to others in order to capture their attention and approval. The belief that the interruption of an emotional relationship can be disastrous also encourages these people to maintain unsatisfactory and inauthentic relationships and, therefore, maintains their sense of inability to cope on their own and their feeling of inauthenticity. The modification of these beliefs is implemented by resorting to various techniques (e.g. imaginative techniques, behavioural experiments, assertiveness exercises, problem solving) that help the patient to increase their sense of efficacy. The therapeutic process takes place through the so-called collaborative empiricism, whereby it is the patient who gradually identifies and learns to meet his or her own needs in functional ways, rather than still expecting others to do so or an omnipotent, saviour-like therapist to do so. For one subtype of patients, a behavioural intervention that can be integrated with Beck and Freeman's therapy has also proved effective: social skills training aimed, in particular, at modulating emotions and impulsive behaviour and developing empathy (by focusing on the emotions and needs of others). Jeffrey Young's schema-focused therapy is a treatment that integrates the cognitive-behavioural approach with object relations and Gestalt approaches. According to this approach, the dysfunctional patterns of 'emotional deprivation' (a belief that other people will not provide the emotional support the person needs), 'imperfection' (a belief that one is imperfect, inadequate and unpleasant or inferior to others) and 'approval seeking' (a belief that one must always seek acceptance at the expense of a real sense of self) are active in patients with histrionic personality disorder. The central aim of this type of therapy is the identification and modification of these patterns, through cognitive, relational, experiential and behavioural strategies (e.g. cognitive restructuring, corrective emotional experiences, empathic confrontation, imaginative exercises, homework) $[3,10,13,39-41]$.

\section{References}

1. APA (2013) DSM-V, Washington.

2. French JH, Shrestha S (2020) Histrionic Personality Disorder. In StatePearls. Link: http://bit.ly/3hJVtiK

3. Perrotta G (2019) Psicologia clinica. Luxco Ed., 1st ed

4. Perrotta G (2020) Bisexuality: definition, humanistic profiles, neural correlates and clinical hypotheses. J Neuroscience and Neurological Surgery 6. Link: https://bit.ly/2LpzwJx

5. Perrotta G (2020) Human mechanisms of psychological defence: definition, historical and psychodynamic contexts, classifications and clinical profiles. Int J Neurorehabilitation Eng 7: 1000360. Link: http://bit.ly/2LiUn1p

6. Perrotta G (2019) The reality plan and the subjective construction of one's perception: the strategic theoretical model among sensations, perceptions, defence mechanisms, needs, personal constructs, beliefs system, social influences and systematic errors. J Clinical Research and Reports 1. Link: https://bit.ly/3hPoGsz

7. Perrotta G (2020) Dysfunctional attachment and psychopathological outcomes in childhood and adulthood. Open J Trauma 4: 012-021. Link: http://bit.ly/2Xo4LYX

Citation: Perrotta G (2021) Histrionic personality disorder: Definition, clinical profiles, differential diagnosis and therapeutic framework. Arch Community Med Public Health 
8. Perrotta G (2020) Narcissism and psychopathological profiles: definitions, clinical contexts, neurobiological aspects and clinical treatments. J Clin Cases Rep 4: 12-25. Link: https://bit.ly/2X8wzzF

9. Perrotta G (2020) Borderline Personality Disorder: definition, differentia diagnosis, clinical contexts and therapeutic approaches. Ann Psychiatry Tream 4: 043-056. Link: http://bit.ly/3rTWR71

10. Gabbard GO (2007) Psichiatria psicodinamica. Cortina Editore, Milano.

11. Perrotta G (2019) Psicologia dinamica. Luxco Ed., 1th ed.

12. Novais F, Araújo A, Godinho P (2015) Historical roots of histrionic personality disorder. Front Psychol 6: 1463. Link: http://bit.ly/3oePG7n

13. Perrotta G (2019) Psicologia generale, Luxco Ed., 1st ed.

14. Ritzl A, Csukly G, Balázs K, Égerházi A (2018) Facial emotion recognition deficits and alexithymia in borderline, narcissistic, and histrionic personality disorders. Psychiatry Res 270: 154-159. Link: http://bit.ly/3rVuR32

15. Perrotta G (2019) Tic disorder: definition, clinical contexts, differential diagnosis, neural correlates and therapeutic approaches. J Neurosci Rehab 2019: 1-6. Link: https://bit.ly/3okeCdy

16. Perrotta G (2019) Anxiety disorders: definitions, contexts, neural correlates and strategic therapy. J Neur Neurosci 6: 046. Link: http://bit.ly/3hGJwuf

17. Perrotta G (2019) Neural correlates in eating disorders: Definition, contexts and clinical strategies. J Pub Health Catalog 2: 137-148. Link: https://bit.ly/3cTvr9m

18. Perrotta G (2019) Post-traumatic stress disorder: Definition, contexts, neural correlations and cognitive-behavioral therapy. J Pub Health Catalog 2: 40-47. Link: https://bit.ly/2WMQCo1

19. Perrotta G (2019) Sleep-wake disorders: Definition, contexts and neural correlations. J Neurol Psychol 7: 09. Link: http://bit.ly/2MzwZxa

20. Perrotta G (2019) Depressive disorders: Definitions, contexts, differential diagnosis, neural correlates and clinical strategies. Arch Depress Anxiety 5 009-033. Link: http://bit.ly/2zSl1Zh

21. Perrotta G (2019) Panic disorder: definitions, contexts, neural correlates and clinical strategies. Curr Tr Clin Med Sci 1: 2019. Link: http://bit.ly/2Xk0d4T

22. Perrotta G (2019) Obsessive-Compulsive Disorder: definition, contexts, neural correlates and clinical strategies. Cientific Journal of Neurology 1: 08-16. Link: https://bit.ly/3hGJ5A7

23. Perrotta G (2019) Behavioral addiction disorder: definition, classifications, clinical contexts, neural correlates and clinical strategies. J Addi Adol Behav 2. Link: http://bit.ly/3pPYf96

24. Perrotta G (2019) Delusions, paranoia and hallucinations: definitions, differences, clinical contexts and therapeutic approaches. Cientific Journal of Neurology 1: 22-28.

25. Perrotta G (2019) Paraphilic disorder: definition, contexts and clinical strategies. Journal of Addiction Neuro Research, Neuro Research 1: 4. Link: http://bit.ly/3q10IRV

26. Perrotta G (2019) Internet gaming disorder in young people and adolescent: A narrative review. J Addi Adol Beh 2. Link: https://bit.ly/3rTbAyZ
27. Perrotta G (2019) Bipolar disorder: definition, differential diagnosis, clinical contexts and therapeutic approaches. J Neuroscience Neurological Surgery 5. Link: https://bit.ly/3hKPdqM

28. Perrotta G (2020) Psychological trauma: definition, clinical contexts, neural correlations and therapeutic approaches Recent Discoveries. Curr Res Psychiatry Brain Disord CRPBD-100006. Link: http://bit.ly/3gbRCto

29. Perrotta G (2020) Suicidal risk: definition, contexts, differential diagnosis, neural correlates and clinical strategies. J Neuroscience Neurological Surgery 6: 114. Link: http://bit.ly/3hUtVaF

30. Perrotta G (2020) Pathological gambling in adolescents and adults: definition, clinical contexts, differential diagnosis, neural correlates and therapeutic approaches. ES J Neurol 1: 1004. Link: https://bit.ly/3rT9H5A

31. Perrotta G (2020) Pedophilia: definition, classifications, criminological and neurobiological profiles and clinical treatments. A complete review. Open $J$ Pediatr Child Health 5: 019-026. Link: http://bit.ly/2Xdyjl9

32. Perrotta G (2020) The concept of altered perception in "body dysmorphic disorder": the subtle border between the abuse of selfies in social networks and cosmetic surgery, between socially accepted dysfunctionality and the pathological condition. J Neurol Neurol Sci Disord 6: 001-007. Link: http://bit.ly/2DOAM5n

33. Perrotta G (2020) Sexual orientations: a critical review of psychological clinical and neurobiological profiles. Clinical hypothesis of homosexual and bisexual positions. Int J Sex Reprod Health Care 3: 027-041. Link: http://bit.ly/3pLwaQb

34. Perrotta G (2020) Cuckolding and Troilism: definitions, relational and clinica contexts, emotional and sexual aspects and neurobiological profiles. A complete review and investigation into the borderline forms of the relationship: Open Couples, Polygamy, Polyamory. Ann Psychiatry Treatm 4: 037-042. Link: http://bit.ly/38fDdKZ

35. Perrotta G (2020) Dysfunctional sexual behaviors: definition, clinical contexts neurobiological profiles and treatments. Int J Sex Reprod Health Care 3: 061 069. Link: https://bit.ly/356izLi

36. Perrotta G (2020) Perrotta Integrative Clinical Interview. LK ed., I ed., 270. Link: https://bit.ly/2Lpz6CX

37. Perrotta G (2020) The structural and functional concepts of personality: The new Integrative Psychodynamic Model (IPM), the new Psychodiagnostic Investigation Model (PIM) and the two clinical interviews for the analysis of personality disorders (Perrotta Integrative Clinical Interview or $\mathrm{PICl}-1$ ) Psychiatry. Link: http://bit.ly/35bcpts

38. Perrotta G (2020) First revision of the Psychodiagnostic Investigation Mode (PIM-1R) and elaboration proposal of a clinical interview for the analysis of personality disorders (Perrotta Integrative Clinical Interview or $\mathrm{PICl}-1$ ) for adults, teenagers and children, Psychiatry.

39. Perrotta G (2020) The strategic clinical model in psychotherapy: theoretical and practical profiles. Journal of Addiction and Adolescent Behaviour 3: 5 Link: http://bit.ly/3n8Ecko

40. Perrotta G (2020) Accepting "change" in psychotherapy: from consciousness to awareness. J Addiction Research and Adolescent Behaviour 3.

41. Perrotta G (2020) Neonatal and infantile abuse in a family setting. Open $J$ Pediatr Child Health 5: 034-042. Link: https://bit.ly/3hGHaeG

Copyright: @ 2021 Perrotta G. This is an open-access article distributed under the terms of the Creative Commons Attribution License, which permits unrestricted use, distribution, and reproduction in any medium, provided the original author and source are credited.

Citation: Perrotta G (2021) Histrionic personality disorder: Definition, clinical profiles, differential diagnosis and therapeutic framework. Arch Community Med Public Health 7(1): 001-005. DOI: https://dx.doi.org/10.17352/2455-5479.000123 